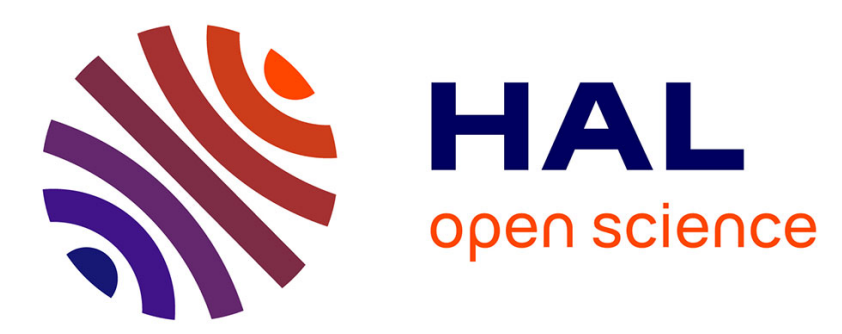

\title{
Constitutional rules and competitive politics: their effects on secessionism
}

\author{
Albert Breton, Pierre Salmon
}

\section{To cite this version:}

Albert Breton, Pierre Salmon. Constitutional rules and competitive politics: their effects on secessionism. [Research Report] Laboratoire d'analyse et de techniques économiques(LATEC). 2002, 37 p., figures, bibliographie. hal-01544536

\section{HAL Id: hal-01544536 \\ https://hal.science/hal-01544536}

Submitted on 21 Jun 2017

HAL is a multi-disciplinary open access archive for the deposit and dissemination of scientific research documents, whether they are published or not. The documents may come from teaching and research institutions in France or abroad, or from public or private research centers.
L'archive ouverte pluridisciplinaire HAL, est destinée au dépôt et à la diffusion de documents scientifiques de niveau recherche, publiés ou non, émanant des établissements d'enseignement et de recherche français ou étrangers, des laboratoires publics ou privés. 


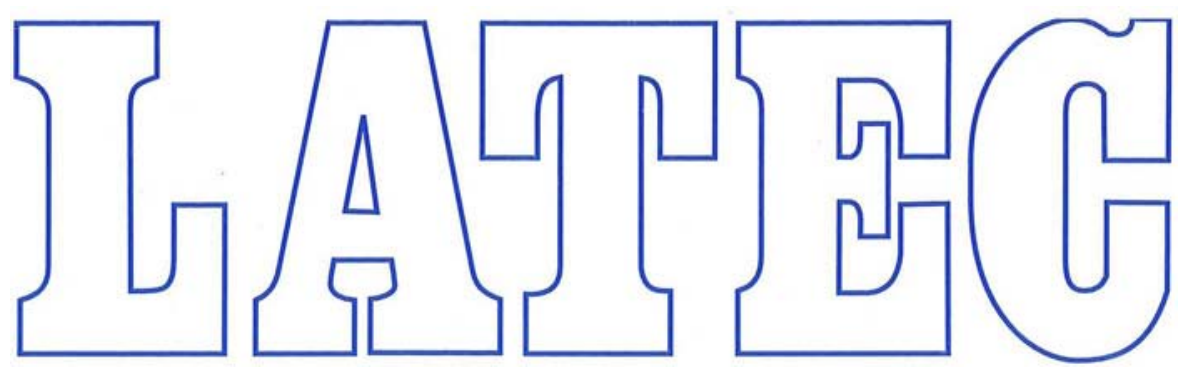

\section{LABORATOIRE D'ANALYSE ET DE TECHNIQUES ÉCONOMIQUES \\ UMR 5118 CNRS}

DOCUMENT DE TRAVAIL

CENTRE NATIONAL

DE LA RECHERCHE

SCIENTIFIQUE

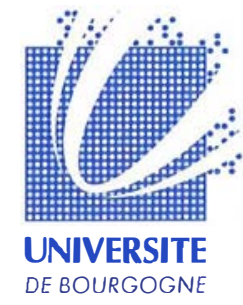

Pôle d'Économie et de Gestion

2, bd Gabriel - BP 26611 - F-21066 Dijon cedex - Tél. 0380395430 - Fax 0380395443

Courrier électronique : secretariat.latec@u-bourgogne.fr 


\section{$\mathrm{n}^{\circ}$ 2002-06 \\ Constitutional rules and competitive politics : \\ their effects on secessionism}

Pierre SALMON

juin 2002 
January 2002

\title{
CONSTITUTIONAL RULES AND COMPETITIVE POLITICS: THEIR EFFECTS ON SECESSIONISM
}

\author{
Albert Breton \\ Department of Economics \\ University of Toronto \\ and \\ Pierre Salmon \\ LATEC \\ Faculté de Science Economique \\ Université de Bourgogne
}

\begin{abstract}
Albert Breton and Pierre Salmon argue that the effects of constitutional rules depend on the nature of political competition and on some meta-rules that contain procedures regulating the application and the modification of constitutional rules. They outline two models of competition - electoral competition and compound government competition - and describe the nature of the transactions between the parties involved in the two corresponding settings. In both, the transactions are over constitutional rules and ordinary goods and services, all of which are arguments in the utility functions of citizens. To make the discussion more concrete, the paper focuses on the demand for political autonomy, a variable which, at the limit, becomes a demand for secession and independence. This allows the specification of some meta-rules applicable to secessionism. In this particular context, it appears that relatively small differences in the content of the meta-rules lead to large differences in equilibrium outcomes.
\end{abstract}

JEL: D72, H77

Key words: constitutional economics, political competition, secessionism 


\section{Introduction}

Constitutional rules (or, more generally, constitutional variables) must be analyzed in competitive settings. These rules can constrain the behavior of public sector actors and ensure that political competition remains active and vigorous. Political competition, in turn, can affect the capacity of constitutions to constrain political action. Among the different ways of modeling political competition in the case of democratic societies, we retain two: a) electoral competition, as understood in the probabilistic voting model; and b) competition among centers of power in compound governments (Breton, 1996).

In that framework, the preferences and opinions of citizens in their capacity as voters or demanders of public policies necessarily count. In the literature, these preferences are usually restricted to goods and services; in what follows, they are defined over constitutional variables as well. ${ }^{1}$ Moreover, we assume that there will necessarily be trade-offs or compensations between goods and services on the one hand and constitutional variables on the other. This is often the case at the level of individual citizens, but it will obtain at the collective level as a matter of necessity. By itself, this creates a first strong linkage among all issues, including the constitutional ones. In addition, a second linkage derives from the fact that decision-makers in the public sector normally function in institutional settings parliaments, cabinets, political parties, for instance - which make it natural and easy to bring together apparently unconnected issues. ${ }^{2}$ Thus, pushed by competition, decision-makers will not ignore the possibilities of trade-offs or compensations and therefore can be expected to engage in various kinds of trades, exchanges or bargains, involving objects of all kinds, constitutional or other.

\footnotetext{
${ }^{1}$ See Salmon (2001a).

${ }^{2}$ This aspect of politics or policy-making is stressed in recent books by Tullock (1998) and Cooter (2000). In the latter, we read (p. 120): "Broad jurisdiction splices independent issues together like the strands of a rope. In contrast, narrow jurisdiction factors politics into independent issues like a mathematician dividing a large number into prime numbers... Splicing widens the scope for bargaining by lowering the transaction costs of political trades" (italics in the original).
} 
In the next section, we provide illustrations of the variables we assume enter the preference functions of citizens as constitutional rules. We also stress some of their characteristics - such as continuity - that are not usually considered in the literature. The discussion makes clear that constitutional variables are numerous and varied. However, to obtain precise results, the trade-off between them and goods and services has to be restricted to a subset of these variables. To give focus to the models of Sections 3 and 4 - concerned respectively with electoral competition and competition in compound governments - we limit ourselves to the subset of rules that define the degree of autonomy (the limit value being secession) of the constituent units of larger jurisdictions - a province in a federation for example. In addition, we distinguish between this subset of rules and exogenous rules identified as meta-rules - which pertain to the procedure governing the implementation of the constitutional rules that control changes in the degree of autonomy. We therefore have two types of constitutional rules, one endogenous and the other exogenous. To economize on space and without loss of generality, we limit ourselves to the analysis of one comparative disturbance, namely a change in average incomes. The effects of that disturbance depend on the content of the meta-rules. Section 5 offers a comparison of the outcomes of the compensation mechanisms in the two models of political competition. Section 6 concludes the paper.

\section{Preferences}

We assume that citizens can be represented by utility functions defined over: a) goods and services (including redistribution), b) the services derived from the set of rules and other variables that define the constitutional set-up (the particular case of meta-rule being discussed at the end of this section), and c) the services derived from the institutions that define economic regimes. The goods and services that enter the utility functions of individual 
citizens are the stuff of microeconomics and public sector economics and are well-known. The set of variables that define the constitutional set-up are, however, less familiar. For purpose of illustration, we mention the nature and the extent of the separation of the executive, legislative, and judicial branches of government, the type and degree of the division of powers among levels of government, the character of the rules governing parliamentary debates, legal procedures governing changes to the constitutional set-up, the specificity of the rules regulating the civil service, the method of cabinet formation and so on. This constitutional set-up also includes whether the governmental system is congressional or parliamentary and whether governments within the system are unicameral or bicameral, the character of the electoral system, the rules pertaining to how judges, commissions of inquiry, and heads of departments (ministries) are appointed, how political parties are financed, the degree of autonomy of central banks, regulatory and administrative tribunals, and other like bodies, the status of the military and constabulary forces, the relations between church and state, and so on. Finally, the constitutional set-up includes compliance to the rule of law, to rights (civil, human, and political), to the principle of equality before the law - a principle sometimes labeled isonomy which was associated to the democratic constitution of Athens, as early as the 6th century B.C. (see Grillo, 1997; Mueller, 2001) - and so on.

The set of institutions which constitutes economic regimes includes elements such as whether the economy is largely market oriented or planned, whether price, wage, rent, and exchange controls are extensively used, whether minimum wage legislation exists, as well as the extent of protectionism, the strength of anti-trust legislation, the definition and enforcement of property rights, the conditions on the use of takings, and others. We therefore accept the point made by Vanberg (1998) that the institutions of economic regimes are elements of overall constitutional set-ups and call all of them - the components of constitutional set-ups and the institutions of the economic regimes - constitutional variables. 
We wish to underline five features of the variables just listed (and others like them) and of the utility functions in which they enter as arguments. First, though our illustrations often refer to stocks - the existing electoral rules, the character of the separation of executive, legislative, and judicial powers, the rules governing parliamentary debates, the bicameral or unicameral nature of governments - what enters the utility functions of citizens are services which flow from these stocks. Constitutional variables are genuine capital assets in that they are costly to design, implement, and alter and because the stream of services they yield are reaped over time.

Second, contrary to what one might be tempted to think, the arguments of utility functions are, in most cases, continuous. That is the case for all those we have listed above. Consider electoral rules, unicameralism and bicameralism, and the autonomy of public nonelected bodies. Discussions of electoral rules - simple majority and proportional representation, for example - are often conducted in a framework that can lead one to think that the choice is between one or the other. A casual look at the real world soon reveals, however, that the two rules are combined in a sufficient number of ways to warrant treating the variable as continuous. Governments can be unicameral or bicameral. The relative powers of the two houses under bicameralism can, however, vary enormously - so much so that a system is more or less bicameral. Finally, the degree of autonomy of public nonelected bodies - the extent to which they operate at arm's length from elected politicians - does, as a matter of observable fact, vary a great deal.

Third, some of the goods and services provided and most, probably all, constitutional variables are pure Samuelsonian public goods. To put it differently, a particular electoral system, a given degree of bicameralism, the degree of autonomy of public bodies, the extent of reliance on markets, once selected will be the same for all citizens, whether that is what they desire or not. 
Fourth, the goods and services as well as the constitutional variables can be independent of each other, complements with each other, or substitutes for each other. To put it differently, if a constitutional variable is reduced by one unit, an individual can be made to remain on the same indifference curve by an increase in the amount of a good such as police protection, unemployment insurance, public broadcasting, or a combination of all of these. Conversely, because constitutional variables are as a rule continuous, an individual can be made to remain at the same level of utility following a decrease in (say) police protection by a change in a constitutional variable.

Even though preferences are genuine, the demands for goods, services, and constitutional variables are initially latent or potential - they are activated by entrepreneurs (as is always the case) and/or by the observation of what obtains in other jurisdictions.

We note also that individual preference orderings may be dominated and shaped by what are, in effect, meta-preferences or basic beliefs. These can include an over-riding commitment to democracy, to principles such as popular sovereignty, a respect for the constitution, and/or to the belief, well expressed in the American Declaration of Independence, that "all men are created equal" in respect of "certain unalienable rights, among which are life, liberty, and the pursuit of happiness". We need not add that the basic beliefs of some individuals may refer to the absolute opposite of the above.

In our framework of analysis, meta-rules have a particular status. Their function is to regulate the trade-offs and the associated compensations between constitutional rules and between these rules and other variables. As already noted, we treat the meta-rules as exogenous. ${ }^{3}$ We also often take them as discontinuous.

\section{Electoral competition}

\footnotetext{
${ }^{3}$ We make this assumption well aware that in the world of experience meta-rules cannot be fully exogenous. See Voigt (1999) for the view that all constitutional rules evolve.
} 
In this section, we concentrate on voting and disregard the existence of competition among different centers of power which will be examined in the next section. Here, compensation operates within political sets-ups that may vary a lot but have in common their reliance on electoral competition, itself animated by the dominant desire of office-holders and their challengers to be elected or re-elected.

\section{i) The general framework}

To study the way compensation operates, we consider exchanges between two "legislators" each elected according to a majority rule. We assume that, in each legislator's district, the incumbent legislator is competing with a single opponent. Both the incumbent legislator and his or her opponent perceive electoral competition as it is conceived in the theory of probabilistic voting: what they are concerned with is the effect of what they do or say - that is, of their 'platform' or 'program' - on the probability of winning, or the expected share of the votes, at the next contest. We stress that the difference between the probabilistic voting and the median voter models is not limited to different ways of conceiving democracy. The probabilistic voting model allows for the possibility that only subgroups of voters have preferences over constitutional rules and for the possibility that these subgroups can make these preferences count in the final equilibrium. Those possibilities - ubiquitous features of the real world - have no place in the median voter model. ${ }^{4}$

In such setting, the logic of Cournot-Nash equilibrium will normally lead to convergence (meaning identity) of the two platforms (Mueller, 1989; Coughlin, 1992; Lafay, 1992). ${ }^{5}$ For our purpose, this means that if, as a consequence of some change in an exogenous variable, the maximization of expected votes by the incumbent candidate $\mathrm{X}$ dictates that she adopts a new policy $\mathrm{Q}$, this also applies to her challenger $\mathrm{Y}$. The electoral prospect of $\mathrm{X}$ (or,

\footnotetext{
${ }^{4}$ For discussions of some limitations of the probabilistic voting model which are not, however contrasted to limitations of the median voter model, see Usher (1994) and Kirchgässner (2000).

${ }^{5}$ Whatever theoretical framework or model one adopts, platform convergence is a source of problems for what one may expect from constitutions (see Salmon, 2001b).
} 
for that matter, $\mathrm{Y}$ ) is not improved compared to the situation before the exogenous change; it is improved only compared to what would have obtained if she had not decided policy Q, and thus had conceded an advantage to her opponent. In other words, because of the intensity of competition between office-holders and their challengers, the behavior of the former is determined (the behavior of challengers also, but this is of no enduring interest to us).

When, as we will see, the decisions of an office-holder are the outcome of a negotiation with some third party (a decision-maker other than his or her challenger), the logic of convergence extends to this situation and remains compelling: were $\mathrm{X}$ not attempting to get the most favorable outcome, this would immediately be exploited by her challenger $\mathrm{Y}$. The need to maximize votes just for the purpose of remaining afloat dictates X's conduct.

We now turn to the exchange between two legislators $\mathrm{L}_{\mathrm{A}}$ and $\mathrm{L}_{\mathrm{B}}$. In each of the two districts $\left(D_{A}\right.$ and $\left.D_{B}\right), L_{A}$ or $L_{B}$ competes with a single opponent or challenger in the perspective of the next election. As noted, the incumbents as well as the challengers are exclusively concerned with winning the election. The voters are concerned with two things: the value taken by a continuous constitutional characteristic (R) and the total net amount of goods and services $-G_{A}$ or $G_{B}$ - available in their district. Legislator $L_{A}$ will exchange some items with, say, legislator $L_{B}$ inasmuch as not doing so would decrease his or her probability of winning the next election, and the same is true of Legislator $L_{B}$.

An important consideration in this setting is whether the total net quantity of goods and services available to the inhabitants of the district - say, $G_{A}$ - is conditional or not on the stand taken by the representative of that district with regard to the constitutional rule. If $G_{A}$ is available unconditionally, it is reasonable to assume that its amount will not affect the value $\left(\mathrm{R}_{\mathrm{A}}\right)$ of the constitutional rule that is electorally optimal for our incumbent legislator (the value of the rule whose endorsement maximizes the probability that he will win the election) as well as for his challenger. In Figure 3.1, the vertical line passing through $R_{A}$ reflects this 
orthogonality assumption: whether $G_{A}$ is measured by $h, j$, or $k$, the electorally optimal value of $R$ remains equal to $R_{A}$.

Now, suppose that the amount of goods and services available in the district is conditional on the position adopted by the legislator with regard to the constitutional rule. More precisely, the district can rely on an unconditional (exogenous) amount of $G_{A}$ equal to $\mathrm{O}_{\mathrm{A}} \mathrm{h}$ but will receive more provided that $\mathrm{L}_{\mathrm{A}}$ changes his stand on $\mathrm{R}$. Curve $\mathrm{V}_{\mathrm{H}}$ in Figure 3.1 indicates, for each considered value of $R$, the minimal amount of $G_{A}$ that $L_{A}$ is compelled by electoral competition within district $\mathrm{D}_{\mathrm{A}}$ to demand for accepting that offer - i.e., the amount necessary to ensure, if no bargaining is involved (see below), that $\mathrm{L}_{\mathrm{A}}$ would receive at least as many votes, or would have at least the same probability of winning, than if he had not departed from his stand at $R_{A}$. It is reasonable to assume that the larger the departure from $R_{A}$ (in either direction), the larger the necessary marginal compensation in terms of $G_{A}$ - hence, the shape of the curve.

[Figure 3.1 goes about here]

If instead of being grafted on an unconditional amount of $G_{A}$ corresponding to $h$, the offer is grafted on an unconditional amount which is larger - for instance, $\mathrm{j}$ - the corresponding curve will be $\mathrm{V}_{\mathrm{J}}$. If he is given the choice between the two curves, the legislator will always chose curve $\mathrm{V}_{\mathrm{J}}$. Even though being on one curve rather than on another entails at equilibrium no difference in the probability of winning the election, electoral competition imposes the choice of the higher one. This is a straightforward implication of the assumptions.

What does not follow from the assumptions is that, in Figure 3.1, $\mathrm{V}_{\mathrm{J}}$ has more curvature than $\mathrm{V}_{\mathrm{H}}$. This property reflects the supposition that the degree of attachment of voters to their preferred value of $R$ - that is, to $R_{A}$ - is akin to a superior good. When $G_{A}$ is small, that is, when the district is relatively poor, a small supplement in $G_{A}$ will "buy" a large departure 
from $R_{A}$ but when $G_{A}$ is large (the district is richer), a large supplement in it will be necessary to get only a small departure from $R_{A}$. If the unconditional amount of $G_{A}$ is increased further, equal for instance to $\mathrm{O}_{\mathrm{A}} \mathrm{k}$ in Figure $3.1, \mathrm{~V}_{\mathrm{K}}$ will have even more curvature than $\mathrm{V}_{\mathrm{J}}$. The same reasoning holds for curves higher than $V_{K}$. We willingly admit that this assumption, although plausible in some contexts, is not always compelling: it may be the case that the poorer the district the more stubborn or uncompromising its voters in their preference for $R_{A}$. In fact, we will also use the assumption that the curves are vertically identical (corresponding to quasilinearity in the function underlying them).

To bring into the analysis the second incumbent legislator $\left(\mathrm{L}_{\mathrm{B}}\right)$, who is also competing electorally with a single opponent in her own district $\left(D_{B}\right)$, we make use of Figure 3.2 in which $R$ is measured vertically instead of horizontally as in Figure 3.1 and $G_{A}$ horizontally instead of vertically. This imparts to the $\mathrm{V}$-curves and to the straight line $\mathrm{R}_{\mathrm{A}}$ the position shown in the diagram. Figure 3.2 is constructed so that the data relating to that second legislator must be read from right to left and upward starting from origin $\mathrm{O}_{\mathrm{B}}$. This applies to $\mathrm{G}_{\mathrm{B}}$, the amount of goods and services available to the inhabitants of the district of this second legislator, to $R_{B}$, the electorally optimal endorsed value of the constitutional rule in the case of unconditional amounts of $G_{B}$, and to the U-curves we provide the second legislator with, which are the equivalent of the first legislator's V-curves and, as the former, are convex with respect to their relevant axis. The distance between $\mathrm{O}_{A}$ and $\mathrm{O}_{\mathrm{B}}$ measures the total amount $\left(\mathrm{G}_{\mathrm{T}}\right)$ of goods and services available in the two districts (that is: $G_{T}=G_{A}+G_{B}$ ).

\section{[Figure3.2 goes about here]}

$R_{A}$ and $R_{B}$ are different but, because the two legislators live in (the two districts are part of) the same country and there may be only one value of R in the country (it is a public good), the exact rule - i.e., the value of $\mathrm{R}$ - that prevails must be the same. We suppose that it is enough that the two incumbent legislators agree on a value of $\mathrm{R}$ for that value to prevail. We 
also suppose that whatever distribution of $\mathrm{G}_{\mathrm{T}}$ they agree upon will be implemented costlessly. This opens up the possibility of reaching an agreement on the value of $R$ by the way of a variation in, or a redistribution of, goods and services.

For expositional purposes, let us choose an out-of-equilibrium point such as D as the original situation. At point $D, G_{A}$ and $G_{B}$ are measured by distances $O_{A} G_{D}$ and $G_{D} O_{B}$ respectively, and the prevailing value of the constitutional rule, read on the vertical axis, is $R_{A}$ (the rule preferred by $L_{A}$ ). Legislator $L_{A}$ is willing to depart from $R_{A}$ provided his district receives a larger amount of $\mathrm{G}_{\mathrm{A}}$. The degree of this willingness (in the absence of bargaining, see below) is indicated by curve $V_{D}$. Now turn to Legislator $L_{B}$. She would accept that her district $D_{B}$ receives a smaller amount of $G_{B}$ provided that rule $R$ takes a value closer to $R_{B}$. The degree to which she would want this (in the absence of bargaining) is indicated by curve $U_{D}$, which passes through $D$. For an equilibrium to obtain, - that is, for no unexploited possibility of reaching a higher curve to remain - a V-curve and a U-curve must be tangent, the locus of equilibrium points being thus the traditional contract curve. Depending on how the exchange situation is specified, equilibrium will necessarily lie somewhere on that contract curve between $\mathrm{E}$ and $\mathrm{F}$.

Our repeated insistence, in the course of defining the V-curves and the U-curves, that there be no bargaining is now readily understood. Loosely speaking, there is a gain to trade, or surplus. However, whatever the equilibrium outcome of the negotiation about that surplus, the probabilities of an electoral victory of $\mathrm{L}_{\mathrm{A}}$ and $\mathrm{L}_{\mathrm{B}}$ against their respective challengers are, at equilibrium, constant. Nonetheless, each of the two legislators is compelled by electoral competition he or she is submitted to in their respective districts to strive for the best bargain possible. Failing to do so would immediately be exploited by their challengers. Thus we do face the typical problem of two-player bargaining for the distribution of a gain to trade or 
surplus and cannot say where the equilibrium will stand on the contract curve between $E$ and F.

In Figure 3.2, the contract curve is extended on the two sides of $E$ and $F$ to show the locus of equilibria whatever the initial situation. Making the plausible assumption that Vcurves and U-curves tend to become straight vertical lines when the amounts of $G_{A}$ and $G_{B}$ respectively tend to zero, the contract curve goes from $X$ (on the $R_{B}$ line) to $Y$ (on the $R_{A}$ line). Suppose that the initial situation had been point $D^{\prime}$ on the $R_{B}$ line instead of $D$ - that is, the same distribution of goods and services but a constitutional rule fitting the rich district $D_{B}$ instead of the poor one $\mathrm{D}_{\mathrm{A}}$. Then, although we have not drawn the corresponding U- and Vcurves, it is clear from the geometry that the exchange would have been very limited, leading to a point on the contract curve XY very close to $\mathrm{D}^{\prime}$ (a little above and on the left). This particular result is, of course, a consequence of our assumption that the richer the district the less likely it is to change its constitutional preferences in exchange for more goods and services. But the more general lesson is that the choice of a rule depends on where we start from - on where exactly is the status quo. When a constitutional characteristic is exchanged against goods and services, this result seems plausible. We will see, however, that, at least in the provincial autonomy context to which we turn now as a specification of the more general framework, this result is not independent of the meta-rules that govern political exchanges.

\section{ii) Meta-rules}

Because we define the meta-rules for the particular provincial setting just mentioned we must make some adjustments in the basic framework discussed so far. First, one of the two electoral districts, $\mathrm{D}_{\mathrm{P}}$, is now a province or region of a country and the other electoral district, $D_{R O C}$, is the rest of the country; we suppose $L_{P}$ and $L_{R O C}$ to have been elected to represent these two districts in the same conditions than those spelled out above. ${ }^{6}$ Second, the

\footnotetext{
${ }^{6}$ Because we assume relations between $L_{P}$ and $L_{R O C}$ to be shaped by the calculus of the probabilistic voting model, we conceive of secession and secessionism in a way which is quite different from the approaches that
} 
constitutional variable is interpreted now as the degree of autonomy of $\mathrm{D}_{\mathrm{P}}$. The maximum value that this variable can take is 1 , corresponding to complete independence following secession. Third, the value of the degree of autonomy which, in the absence of any compensation in terms of goods and services, maximizes the expected votes obtained by $\mathrm{L}_{\mathrm{P}}$ and $L_{R O C}-R_{P}$ and $R_{R O C}$, respectively - is 1 for $L_{P}$ and a relatively low value for $L_{R O C}$, as indicated in Figure 3.3. That figure should be read in the same way as Figure 3.2 (the origins, however, now being called $\mathrm{O}_{\mathrm{P}}$ and $\left.\mathrm{O}_{\mathrm{ROC}}\right)$. Fourth, the resources in goods and services available to the inhabitants of $D_{P}$ and $D_{R O C}$ are respectively $G_{P}$ and $G_{R O C}$. They are measured horizontally exactly in the same way as resources were measured in Figure 3.2.

\section{[Figure 3.3 goes about here]}

We distinguish between two possible meta-rules. One says that secession, that is, the change from a degree of provincial autonomy different from one to a degree equal to one, is exactly alike any other change in the degree of autonomy in that it must receive the agreement of both $L_{P}$ and $L_{R O C}$. The other possible meta-rule says that the secession of the province by the way of a unilateral decision of $\mathrm{L}_{\mathrm{P}}$ is possible. In other words, it says that all changes must be agreed on by both legislators except secession. As we show, the effects of exogenous disturbances depend on which of the two meta-rules applies.

\section{iii) Comparative statics}

Assume that the meta-rule in force is the first one, that the exogenous disturbance is an increase in income in $\mathrm{D}_{\mathrm{P}}$, and that the original situation corresponds to point $\mathrm{D}$ in Figure 3.3. Legislator $\mathrm{L}_{\mathrm{ROC}}$ is willing to depart from $\mathrm{R}_{\mathrm{ROC}}$ provided her district receives a larger amount of goods and services. This willingness is reflected by U-curves, one of which, $U_{D}$, passes through D. Similarly, before the exogenous income increase in province $D_{P}, V$-curves express the willingness of legislator $L_{P}$ to exchange variations in the degree of autonomy of

model democracy using the median voter model. See for example Alesina and Spolaere (1997), Bolton, Roland and Spolaore (1996), Rota Graziosi (2001). 
his province for changes in the distribution of goods and services. One of these curves is $V_{D}$, which passes through point D.

Point $\mathrm{D}$ is not an equilibrium. One possible equilibrium point (at which a U-curve, at least as "high" as $\mathrm{U}_{\mathrm{D}}$, and a V-curve, at least as "high" as $\mathrm{V}_{\mathrm{D}}$, are tangent) is $\mathrm{E}$. The position of $E$ expresses the fact that it was electorally optimal for both $L_{P}$ and $L_{R O C}$ to have some redistribution of goods and services in favor of $D_{R O C}$ in exchange for a degree of autonomy of the province higher than the one electorally preferable (in the absolute) in $\mathrm{D}_{\mathrm{ROC}}$. In other words, it is as if the province had paid in goods and services for an augmented degree of autonomy.

Suppose now that the income of $\mathrm{D}_{\mathrm{P}}$ increases. The effect of that, as reflected in Figure 3.3 , is a translation to the left of both the left vertical axis (origin $O_{P}$ moves left to $O_{P}$ ) and the whole family of V-curves - which (because we consider only the part of the set which can be depicted within the limits of the diagram) we relabel W-curves. By contrast, U-curves are not affected (in addition, because $D_{R O C}$ is much larger than $D_{P}$, the U-curves that can be represented in Figure 3.3 should, reflecting quasi-linearity, be assumed to be identical, with constant curvature). One of the $\mathrm{W}$-curves is curve $\mathrm{W}_{\mathrm{E}}$, which passes through point $\mathrm{E}$. Assuming, as in Figure 3.1, that the degree of attachment of voters to their electorally preferred value of the constitutional rule (here the degree of autonomy) is a superior good, curve $\mathrm{W}_{\mathrm{E}}$ has more curvature (with respect to the vertical axis on the left) than the V-curve passing through $\mathrm{E}$. As a consequence, $\mathrm{E}$ is not an equilibrium any more. The new equilibrium is, say, point $F$. Again a higher degree of autonomy for $D_{P}$ has been exchanged for more redistribution in favor of $D_{\text {ROC. }}$. If the windfall to the province had occurred when the initial position D was still prevailing, the relevant W-curve would, like the relevant U-curve, have passed through $\mathrm{D}$ and a position different from $\mathrm{F}$ would have been agreed upon. This shows that, under this first meta-rule, the exact time sequence of constitutional adjustments and 
increases in the exogenous income of $D_{P}$ - the exact "history" of the relationship and exogenous events - counts, even though there is no transaction cost or imperfect information.

Suppose now that the meta-rule is the second one: the secession of the province by the way of a unilateral decision of $L_{P}$ becomes possible. In other words, now all changes must be agreed on by both legislators except secession. Under the first meta-rule, the reasoning concerned only the part of the diagram on the left of vertical line $G_{D} Z$. Under the second meta-rule, starting again from $\mathrm{D}$, the whole left part of the diagram becomes irrelevant. What counts is the initial distribution of goods and services $G_{D}$. To simplify the analysis, we assume that initial distribution to apply also when the province is independent, that is at point $\mathrm{Z}$. Curve $V_{Z}$, which passes through $Z$, expresses the willingness of $L_{P}$ to give up some degree of autonomy of the province against a redistribution of goods and services in its favor. If there is no such redistribution, secession obtains. Curve $U_{Z}$ expresses the willingness of $L_{R O C}$ to accept a redistribution of goods and services in favor of the province to avoid its secession. Equilibrium is, say, at point $\mathrm{E}^{\prime}$.

We introduce now the income increase in the province. For the same reasons as before, $\mathrm{V}$-curves are replaced by $\mathrm{W}$-curves, and in particular curve $\mathrm{V}_{\mathrm{Z}}$ by curve $\mathrm{W}_{\mathrm{Z}}$. Equilibrium is now at point $\mathrm{F}^{\prime}$. If there was a second income increase in $\mathrm{D}_{\mathrm{P}}$, and consequently W-curves had to be replaced by W'-curves endowed with even more curvature (as seen from the left axis), the position of curve $\mathrm{W}_{\mathrm{Z}}^{\prime}$ on the diagram shows that it could be the case in the model that both legislators agree on secession.

If we compare the stories under the two meta-rules, the one with unilaterally decided secession impossible and the other where it is possible, two points emerge that are worth stressing. First, whereas, the history of the relationship counts in the first case, it does not in the second. Second, the actual level of autonomy is not very different in the two cases but the 
redistribution of goods and services is dramatically reversed. ${ }^{7}$ If we compare point $\mathrm{E}^{\prime}$ with point $\mathrm{E}$ - which prevailed when secession by unilateral decision of the province was precluded - we observe that there is no variation, or not much variation, in the degree of autonomy but that the redistribution of goods and services is now in favor of the province. After the income increase, the same is true when we compare points F and $\mathrm{F}^{\prime}$. In other words, in this model, the right to secede unilaterally is highly valuable in terms of goods and services. We might want to derive from this the prediction that even voters of the province who do not favor secession have good reasons to value the right for the province to secede unilaterally (whereas, conversely, voters in the rest of the country who do not really care about secession have nonetheless tangible reasons to be hostile to that right). ${ }^{8}$

\section{Competition in compound governments}

The organization of this section is the same as that of the preceding one. We present first the general framework of analysis, followed by a description of the meta-rules, and by some comparative statical exercises.

\section{i) The general framework}

Given the preferences of citizens, the response of suppliers to these preferences will depend on the mechanisms in place on the supply side. One such mechanism derives from the assumption that governmental systems are competitive as in Breton (1996). Three buildingblocks are needed to make that assumption operational. A first one pertains to the character and structure of governmental systems; a second to the relationship between the centers of power that constitute governmental systems and the citizenry; and a third to the nature of the competitive interaction among centers of power.

\footnotetext{
7 The result is akin to that generated by the Coase Theorem.

${ }^{8}$ For a completely different approach to the pre-secession effects of explicit secession rules, see Bordignon and Brusco (2001).
} 
Democratic governmental systems are made up of a multiplicity of centers of power, some of which are elected, others not. Which centers of power are elected varies a great deal from country to country. In parliamentary systems like those found in Canada, France, Italy, and the United Kingdom, the executive is typically elected. In a congressional system as that which exists in the United States, the head of the Executive is elected, but other members of the Cabinet are not. In certain bicameral systems, both houses are elected, in others only one is. In general, the judiciary is not elected, but there are important exceptions.

There is a great variety of nonelected centers of power. Among them, one finds government departments or ministries, public enterprises, military and constabulary forces, central banks, intelligence bureaus, granting bodies, commissions of inquiry, and tribunals of all sorts.

To understand the nature of the relationship between citizens and centers of power, assume that the particular constitutional variable on which we focus is a pure public good. If the citizens to whom the variable is provided differ in their preferences, the quantity supplied may satisfy some individuals, but of necessity if exactly the same quantity of the good is made available to all, some citizens will be off their demand curves and suffer utility losses. This idea can be given diagrammatic representation. In Figure 4.1, let the constitutional variable $\mathrm{R}$ be provided at an exogenously set taxprice $\tau^{*}$. At that price, a given individual will demand $\mathrm{R}^{*}$ of $\mathrm{R}$. If the quantity of $\mathrm{R}$ actually supplied is either larger or smaller than $\mathrm{R}^{*}$, the individual will suffer a loss in welfare equal to $a b c\left(=\lambda_{1}\right)$ or aef $\left(=\lambda_{2}\right)$ depending on whether the quantity provided is larger or smaller than the quantity demanded.

\section{[Figure 4.1 goes about here]}

It is possible to compensate the individual for utility losses by changing the quantity supplied of a substitute commodity that will shift the d-curve in Figure 4.1 and, at the limit, eliminate the $\lambda_{1}$ or $\lambda_{2}$ welfare loss. If $\mathrm{R}$ has a complement, the response will be more 
complicated - it will usually call for variation in the quantity of more than one substitute - but the underlying logic is the same.

We now assume that all centers of power maximize expected consent which for elected centers we take to be strictly proportional to expected electoral support or votes. ${ }^{9}$ We define expected consent $\left(\mathrm{EC}_{\mathrm{a}}\right)$ as the probability that citizen ' $\mathrm{j}$ ' will grant her consent to center of power 'a'. Formally, we have:

$$
\mathrm{EC}_{\mathrm{a}}=\Sigma_{1,2, \ldots, \mathrm{J}} \phi_{a}^{j} \quad 1 \geq \phi_{a}^{j} \geq 0
$$

in which $\phi_{a}^{j}$ is the subjective probability of center of power 'a' that $\mathrm{j}$ will grant it her consent.

We now borrow from the probabilistic theory of voting (see Calvert, 1986) the notion that the probabilities of consent $\left(\phi_{a}^{j}\right)$ are continuous and twice differentiable functions of the actions of centers of power, which in the present context means that they are functions of utility losses $(\lambda)$. To be specific, we assume that there are $N$ elected and non-elected centers of power, indexed $n(=1,2, \ldots, N)$, and that the probability that citizen $\mathrm{j}$ will grant her consent to one of them, let us say center ' $a$ ', is a function of the utility losses which that center and the others impose on ' $\mathrm{j}$ '. We then have:

$$
\phi_{a}^{j}=\phi_{a}^{j}\left(\lambda_{a}^{j}, \lambda_{n}^{j}\right) \quad \forall \mathrm{j}, \mathrm{n} \neq \mathrm{a}
$$

with $\partial \phi^{j}{ }_{a} / \partial \lambda_{a}^{j}<0$ for all j's and $\partial \phi_{a}^{j}{ }_{a} / \partial \lambda_{n}^{j}>0$ for all j's and all $\mathrm{n} \neq \mathrm{a}$. We also borrow from the probabilistic theory of voting the assumptions that the $\lambda_{n}^{j}$ functions are strictly concave in $\lambda_{a}$ and strictly convex in $\lambda_{n}$ (with $\mathrm{n} \neq \mathrm{a}$ ).

A consideration of equation (4.2) reveals that centers of power necessarily compete with each other. In other words, equation (4.2.) tells us that the probability that citizen ' $\mathrm{j}$ ' will give her consent to center of power 'a' depends on what 'a' does, but also on what all other N-1 centers of power do. Since these last centers must be assumed to be seeking their own advantage and not that of 'a', it follows that they will, of necessity, be competing with 'a' and,

\footnotetext{
${ }^{9}$ The best empirical proxy for consent is "public opinion" - dimensions of which are regularly measured by opinion polls.
} 
incidentally, with each other. It also discloses that the electoral success of an elected center of power depends on the actions of other centers of power, including nonelected ones. To put it differently, the expected vote of an elected governing party can be adversely affected not only by the actions of opposition parties, but also by the actions of nonelected centers of power such as a supreme court, a commission of inquiry, or a central bank.

The interaction among centers of power is best described by the colloquial expression "checks and balances". To be balanced - "equipoised" in an older language (see Panagopoulos, 1985) - centers of power must possess sufficient freedom of action and power to stand their ground and defend their interests in competitive struggles with other centers of power. Checking - standing one's ground and defending one's interests - does not always, indeed does not usually, mean using instruments to block particular outcomes by force or coercion, but refers instead to engaging in the sort of behavior which is associated with another felicitous political colloquialism which holds that "politics is the art of compromise". ${ }^{10}$ Compromising must not, however, be conceived as pertaining primarily to the negative actions of giving up on, backing down from, or renouncing an initial position. Instead, it should be thought as belonging to the class of positive activities associated with creative and innovative Schumpeterian entrepreneurship.

We formalize the "checking or compromise process" by assuming that more than one center of power are involved, at some point in time $\mathrm{t}=0$, in the design and production of bundles $\left(\mathrm{B}_{0}\right)$ of goods, services, and constitutional variables which are fully described by a vector of Lancasterian (1966) characteristics $Z_{w 0}(w=1,2, \ldots, W)$. For any one bundle (i) in the set of bundles, we have

$$
\mathrm{B}_{0}=\left(\mathrm{Z}_{\mathrm{wi} 0}\right) \quad \forall \mathrm{w}
$$

\footnotetext{
${ }^{10}$ The Canadian diplomat Lester B. Pearson, Nobel Peace Laureate and later Prime Minister, is said to have remarked that "diplomacy is letting someone else have your way". (Vancouver Sun, March 18, 1965).
} 
We also assume that the demand for each $\mathrm{Z}_{\text {wio }}$ is a function of the availability (provision) of all other characteristics $Z_{\mathrm{v} 0}(\mathrm{v}=1,2, \ldots \mathrm{w}-1, \mathrm{w}+1, \ldots \mathrm{V})$, and of the taxprices of all $Z_{\mathrm{w} 0}$, as well as of the $\mathrm{m}(=1,2, \ldots \mathrm{M})$ prices of market goods and services:

$$
\mathrm{Z}_{\mathrm{wi} 0}=\varphi\left(\mathrm{Z}_{\mathrm{v}}, \tau_{\mathrm{v} 0}, \mathrm{p}_{\mathrm{m} 0}\right)
$$

with $\varphi_{1}, \varphi_{2}$, and $\varphi_{3}$ all $\geq 0$; where $\varphi_{1}=\partial \varphi / \partial Z_{v}$, etc. In other words, given $\tau_{i o}$, the position of the demand curve for characteristic $Z_{i 0}$ in bundle (i) will shift as the volume supplied, the taxprices of other characteristics, and the prices of market goods and services are varied.

The checking or compromise process can be illustrated by examining the behavior of two centers of power - 'a' and 'b' - to each of which is attached a homogenous constituency $-c_{1}$ and $c_{2}$. To describe the process in the simplest way possible, assume that initially the situation is as portrayed in Figure 4.2. There, the exogenously given taxprice is $\tau^{*}$ and the volume of a constitutional characteristic $Z_{10}$, which ' $b$ ' proposes to implement, is $Z_{0}^{\prime}$. At point $d, c_{2}$ experiences zero utility loss and is, therefore on its demand curve, whereas $c_{1}$ is off its demand curve (a section of which is shown as $c e$ ) and suffers a utility loss equal to $c d e$. As a consequence 'a' will check ' $b$ '. Let us assume that the checking is successful in the sense that it shifts $c_{1}$ 's demand curve in such a way that it now goes through point $d$. That will happen if the concessions made by 'b' lead to a compromise that cause a change of the "right" magnitude in the design and production of one or more other characteristics of the constitutional variables and/or of the goods and services to which $Z_{10}$ belongs, a change in the design and production of characteristics of other constitutional variables and/or goods and services, and/or a change in the position of supply and demand curves for market goods and services through changes in the relevant taxes and subsidies, while the position of $c_{2}$ 's demand curve was made to continue to run through point $d$. In general, of course, $c_{2}$ 's demand curve will shift. However, if perfect information is available to centers of power, a "tâtonnement" mechanism defined by the competitive checking or compromise process will lead to the 
complete elimination of utility losses. If information is imperfect - the position of demand curves not well-known - some utility losses will remain in equilibrium, but it will be by an amount consistent with the cost of acquiring more information.

\section{[Figure 4.2 goes about here]}

When the checking process has worked itself through, all constitutional variables and the flows of all goods and services in any one bundle will be in equilibrium. In other words, even if the actual implementation of the compensation principle is drawn out and complicated, it will lead to an equilibrium vector of goods, services, and constitutional variables. In the absence of disturbances, at $\mathrm{t}=0$ the equilibrium will be stationary, and the flows of goods and services made available to citizens - the volume of police protection, of law and order and of justice, the size of family allowances, the level of international diplomacy, and all the others will be observable and, in principle, measurable. However, in regards to the flow of services derived from the stock of constitutional variables, nothing is observable. The electoral rules in place are equilibrium rules and, by definition, receive the assent of citizens. The same will be true for the degree of separation of the executive, legislative, and judicial branches, the level of bicameralism, the extent of interjurisdictional decentralization, the relative size of the market sector, and so on.

The foregoing is an obvious point, but to the extent that the implementation of the compensation principle leads to outcomes that are at or near to equilibrium outcomes, it may help understand why a large body of opinion holds to the view that citizens in general do not have preferences over the characteristics of constitutional variables. Indeed, only when citizens find themselves significantly away from equilibrium will they reveal these preferences.

Running the process for different taxprices will trace a complete demand curve for the services of the constitutional characteristic $Z_{10}$. Checking processes are therefore true 
the nature of the exogenous disturbance, on the set of centers of power that would participate in the checking process, and on the particular characteristics of the autonomy variable over which the checking is to take place. In the case in which a marginal increment in autonomy would lead to secession and independence of $\mathrm{P}$, the meta-rules conditioning the outcome would include the extent to which the ability of the province to secede as well as its ability to make a successful break can be affected by ROC. We examine both instances in the next section.

\section{iii) Some comparative statics}

Let us assume that in the bundle of goods, services, and constitutional variables produced in the initial equilibrium, one constitutional variable is a given degree of autonomy for a province in a given country, namely $\mathrm{A}_{\mathrm{P} 0}$. To appreciate what happens when that equilibrium is disturbed, it is necessary to understand that $A_{P 0}$ is constituted of a set of characteristics which, in effect, define what the word 'autonomy' means. Some of these characteristics pertain to the role (formal and informal) of the province in influencing (say) monetary, fiscal, health care, and immigration policies in ROC; the weight of the province in the appointment of persons to different boards, tribunals, and councils in ROC; the capacity of the province to act without coordinating with other governments in matters such as labor mobility, subsidies to capital investment, the promotion of exports which affect ROC generally; and so on.

The checking process that produces $A_{P}$ - that assembles the characteristics that define a particular level of $A_{P}$ - requires the participation of many centers of power housed in the central government of the country and in the provincial and territorial governments.

Let us now consider an exogenous disturbance which takes the form of an increase in the average income of P's population. Let us further assume that this exogenous increase in income leads to an increase in the demand for $A_{P}$ - the size of which depends on the income elasticity of the demand for $A_{P}$, whose size, in turn, we suppose, depends on the ratio of the 
revelation mechanisms. The processes and mechanisms do not, however, generate a unique bundle $\left(B_{t}\right)$ made of a given volume of goods and services and a given value of constitutional variables. It will, indeed, have been constructed by combining a subset of characteristics from the set of all available characteristics. There are a great many such subsets. The one constructed at a particular moment of time will depend on chance events such as the number and identity of the centers of power admitted to participate in the checking process, the order of intervention of centers of power in checking, the control over characteristics exercised by different centers of power, the differences in the personalities of those engaged in the checking processes, and so on. As a consequence, checking processes generate a multiplicity of equilibrium states or $B_{t} s$.

\section{ii) The meta-rules}

The foregoing brief description of the workings of competition in compound governments has made no reference to the role of meta-rules in the determination of equilibrium outcomes. In this subsection, we introduce some relevant meta-rules before observing how they influence outcomes in the discussion of the next subsection.

The constitutional variable we have chosen to illustrate our basic position is still the degree of autonomy of a province $(\mathrm{P})$ in a given country, a variable which, once normalized, continues to take values between zero and one, with one representing secession. In the preceding section, the meta-rule concerning secession affected all negotiations even when secession was not the issue. With the right to secede unilaterally in the background, we saw that the direction of transfers between $\mathrm{P}$ and the rest of the country (ROC) could be the reverse of what obtains under the meta-rule that unilateral secession cannot occur. In this section, meta-rules serve to differentiate changes in the demand for autonomy when these changes do not entail secession and independence from those changes which do. In the case in which the marginal change in autonomy does not lead to secession, the outcome depends on 
number of federalists to secessionists in the province, being smaller the larger the ratio. However, the increase in the demand for autonomy, in this first case, falls short of being a demand for secession. The government of $\mathrm{P}$ knows that $\mathrm{A}_{\mathrm{P}}$ is crafted by the centers of power listed above and it, consequently, knows that the increment in demand for $A_{P}$ cannot be for an across-the-board increase in all the characteristics that define $A_{P 0}$. An across-the-board increase in all characteristics would, indeed, jam or block the checking process and lead to zero increase in $A_{P}$, simply because the give and take associated with the checking process could not take place. $\mathrm{P}$ must therefore select one or a few characteristics as the object or objects of its increased demand for $A_{P}$. Let us call that characteristic or set of characteristics at time $\mathrm{t}=1, Z_{\mathrm{P}}(\alpha, 1)$, which is greater than $Z_{\mathrm{P}}(\alpha, 0)$, the flow of the set of characteristics $\alpha$ prevailing at $\mathrm{t}=0$. This is shown in Figure 4.3 which also portrays the utility loss $(a b c)$ suffered by $P$ - given $Z_{P}(\alpha, 0)$ - as a consequence of the income induced shift in $d$ from $d(0)$ to $d(1)$.

[Figure 4.3 goes about here]

Will P get what it wants? In the absence of information problems, the answer to that question depends on the checking process operating to make utility losses for the constituents of all centers of power equal to zero. If one focuses on $\mathrm{P}$ alone as represented in Figure 4.3, as long as the $Z_{P}(\alpha, 0)$ determined in $t=0$ persists, the new demand curve $d(1)$ implies a utility loss of $a b c$. That loss can be reduced to zero in a number of ways. For example, $\mathrm{P}$ can be granted $Z_{P}(\alpha, 1)$. Or it can be provided with a substitute to $Z_{P}(\alpha, 1)$ that will return $d(1)$ to $d(0)$. The shift in $\mathrm{d}(1)$ needs not, however, be complete, in which case $a b c$ can be reduced to zero by granting some $Z_{P}\left(\alpha, 1^{\prime}\right)$ intermediate between $Z_{P}(\alpha, 0)$ and $Z_{P}(\alpha, 1)$ depending on how perfect the substitute is.

The substitute that shifts $d(1)$ is in the nature of a transfer from the other centers of power to $\mathrm{P}$ and will create a utility loss for the constituents of these centers. Adjustments 
therefore have to take place elsewhere. We assume, as we did earlier, that these adjustments will be governed by a tâtonnement process that leads to an overall equilibrium.

Consider now an exogenous increase in average incomes in $\mathrm{P}$ which leads to an increased demand for autonomy sufficiently large to be, in effect, a demand for secession and independence. We have to this point assumed the taxprice of $Z_{P}(\alpha, t)$ to be given and the checking process to be carried out at that price. We must now recognize that the taxprice of autonomy, and therefore of secession, can change as a consequence of variations in "technological" or "institutional" factors - in the meta-rules - that will bring about changes in the position of the supply curve. In Figure 4.3, the displacement of the supply curve raises the unit prize of autonomy to $\mathrm{P}$ from $\tau(\alpha, 0)$ to $\tau(\alpha, 1)$. The utility loss of $a b c$, caused by the exogenous increase in average incomes has been wiped out.

An example of such a technological-institutional meta-rule change is the bill, informally known as the "clarity" bill, which was recently enacted in Canada. That Act of the Canadian Parliament does not affect the right of the Government of Quebec to make unilateral decisions regarding the referendums on secession, although it does affect other meta-rules. In particular, it specifies that unless the referendum question is "clear"11 and unless the fraction of the Quebec population voting in favor of secession is "sufficiently large", the centers of power in the governments of ROC would not be obligated to negotiate with Quebec - would not have to enter into a checking process - even if the Government of the province declared that it had "won" the referendum. ${ }^{12}$

The Clarity Act, it would appear, reduced the supply of $Z_{P}(\alpha, t)$ and thus raised its taxprice. If the increase in $\tau(\alpha, t)$ had happened to be equal to $\tau(\alpha, 1)-\tau(\alpha, 0)=a f$, then the

\footnotetext{
11 In 1982 and again in 1995, the referendum questions crafted by the Quebec government were paragons of obscurity.

${ }^{12}$ The Clarity Act applies to all provinces. We write 'Quebec' because that is the province with the strongest secessionist population at this moment. For factual information on the economic aspects of secessions and secessionism in a large number of countries, see Bookman (1993).
} 
quantity of $Z_{P}(\alpha, t)$ demanded by Quebec - even with a larger average income - would continue to be $\mathrm{Z}_{\mathrm{P}}(\alpha, 0)$ and the utility loss in Quebec would have been wiped out completely, as can be seen in Figure 4.3. If the increase in the taxprice happened to be less than af, the utility loss could still have been made equal to zero either by a judicious increase in $Z_{P}(\alpha, t)$, or in one or more of its substitutes, or by a combination of both.

We possess no information on the size of the increase in $\tau(\alpha, t)$ following the enactment of the Clarity bill and, a fortiori, on the reduction in utility losses which the increase in the demand for $A_{P}$ on the part of the Quebec government has created. It is remarkable, however, that notwithstanding the serious efforts of the Parti Québécois government - Quebec's secessionist government - to mobilize public opinion in Quebec against the bill, polls indicate that the bill received the overwhelming support of Quebeckers. The increase in the taxprice of $Z_{\mathrm{P}}(\alpha, t)$ must have been nearly equal to af. In other words, it would appear that the Clarity Act, though it in no way affected the right of Quebec to act unilaterally in matters related to the holding of referenda on secession and independence, did reduce the demand for autonomy and therefore secession - by increasing its supply price.

\section{Comparing the outcome of compensation in the two models}

The model of Section 3 places in center stage negotiations between incumbent legislators negotiations in which compensations play a central role. The model of Section 4 gives the same place to a checking and compromise process in which compensations also play a basic role. In the remainder of this section, we point to a difference between the two models which has so far not be mentioned.

In the case of electoral competition, the fact that there is a "gain from trade" (recall the reservations to the use of that term formulated in Section 3) for legislators does not translate directly into one for voters. Within one district, the compensation between what is gained on one side of the transaction and what is lost on the other takes place within the maximization 
of an aggregate variable: the sum of the probabilities that individuals will vote for the incumbent. In turn, these probabilities depend not only on the individual utilities derived from the platforms of the incumbent and his or her opponent but also on the responsiveness of these probabilities to variations in the platforms. Thus, as a result of the transaction between the two incumbent legislators, some voters in both districts receive a benefit and partake in a cost, other voters receive benefits without paying anything, others still contribute to costs without receiving benefits. To illustrate, if the representative of the first jurisdiction accepts an increase in the value of the constitutional rule $\mathrm{R}$ in exchange for more subsidies given to his or her district, and if the subsidies benefit to various degrees all the voters in the district, this constitutes an "undeserved" benefit for the voters who in any case were in favor of an increase in $\mathrm{R}$. Conversely, in the other district, there are voters who pay extra taxes although they are displeased by the change in R. They clearly lose from the transaction. Should we expect the legislators to attempt to compensate losers by the way of taxes imposed on winners? This would be very detrimental to the objective of vote maximization. Moreover, because sensitiveness may play as large a role as utility in the maximization formula, it is not even sure that such compensation would, even in principle, be possible. As a consequence, there can be no general presumption that the exchanges undertaken by the legislators are welfare enhancing and it is certainly improper to say that a district as a whole gains or loses from a transaction struck by its representative.

The matter is different in the case of the competitive compound government model. There, the assumption of perfect competition among a large number of centers of power on the supply side justifies multiform checking processes that, at the limit (that is when stationary equilibrium is reached) eliminate all utility losses at the level of individual citizens or, more generally, at the level of all individuals who are in some sense empowered. The compensations that underlie these processes are highly disaggregated whereas constitutional 
rules and the exact values that they take are on the contrary highly aggregated, being almost always in the nature of pure public goods. In that framework compensation involving only constitutional rules would be difficult to achieve. But, under our approach, this means that compensation between constitutional characteristics and goods and services, which are in most cases private goods, apportionable at the level of individuals, is highly relevant to the understanding of constitutional change. It should also be noted that, inasmuch as compensation is complete, and contrary to the electoral model, the notion of a gain achieved by the change of a constitutional rule is necessarily defined at the level of individuals, and there must be a presumption that the exchanges are in a sense welfare enhancing.

\section{Conclusion}

The effect of constitutional rules, we have argued, depends on the nature of political competition and on the content of exogenous meta-rules that embody the procedures regulating the application and the modification of constitutional rules. Two models of competition - electoral competition and compound government competition - were outlined and the nature of the transactions between the parties involved described. In the two models, the transactions are over constitutional rules and ordinary goods and services, all of which are arguments in the utility functions of possibly all citizens but, in general, of only a subset of citizens who, however, will have an impact on outcomes given the assumption regarding the probabilistic nature of political competition.

Because the implementation of constitutional rules is always affected by procedural meta-rules, it is necessary to select a particular constitutional rule to examine the impact of a given meta-rule. We have chosen to focus on the constitutional rule associated with the demand for political autonomy, a variable which, at the limit, becomes a demand for secession and independence. A concentration on this phenomenon allows us to give a precise meaning to the effects of a procedural meta-rule. We found that relatively small differences in 
the content of the meta-rules led to large differences in equilibrium outcomes. Whether that conclusion can be generalized to all constitutional rules for which meta-rules are significant is a question we cannot answer. It is certainly one deserving further attention.

To make the discussion more concrete, the paper focuses on the demand for political autonomy, a variable which, at the limit, becomes a demand for secession and independence. A concentration on this specific phenomenon allows us to give a precise content to some meta-rules applicable to secessionism. In this particular context, we discover that relatively small differences in the content of the meta-rules lead to large differences in equilibrium outcomes. Whether that conclusion, derived from a concentration on a concrete application, can be generalized to all situations in which meta-rules are significant variables is a question that we cannot answer. It is certainly one deserving of future attention.

\section{References}

Alesina, Alberto \& Spolaore, Enrico (1997), "On the number and size of nations", Quarterly Journal of Economics, Vol. 112, no. 4, 1027-1056.

Bolton, Patrick; Roland, Gérard \& Spolaore, Enrico (1996), "Economic theories of the breakup and integration of nations", European Economic Review, Vol. 40, nos. 3-5, 697-705.

Bookman, Milica Zarcovic (1993). The Economics of Secession (London: Macmillan).

Bordignon, Massimo \& Brusco, Sandro (2000). "Optimal secession rules", European Economic Review, Vol. 45, no. 10, 1811-1834.

Breton, Albert (1996), Competitive Governments. An Economic Theory of Politics and Public Finance (New York: Cambridge University Press).

Calvert, Randall L. (1986), Models of Imperfect Information in Politics (Chur, Switzerland: Harwood Academic Publishers).

Cooter, Robert C. (2000), The Strategic Constitution (Princeton: Princeton University Press).

Coughlin, Peter J. (1992), Probabilistic Voting Theory (Cambridge \& New York: Cambridge University Press).

Grillo, Michele (1997), "Democracy, Competition, and the Principle of Isonomia: An Economic Analysis of the Political Exchange as an Incomplete Contract", in Albert Breton, Gianluigi Galeotti, Pierre Salmon, and Ronald Wintrobe, eds., Understanding Democracy (New York: Cambridge University Press), 47-63. 
Kirchgässner, Gebhard (2000), "Probabilistic Voting and Equilibrium: An Impossibility Result", Public Choice, Vol. 103, Nos. 1-2, 35-48.

Lafay, Jean-Dominique (1992), "La théorie probabiliste du vote", Revue d'Economie Politique, Vol. 102, No. 4, July-August, 487-518.

Lancaster, Kelvin J. (1966), "A New Approach to Consumer Theory", Journal of Political Economy, Vol. 74, No. 2, April, 132-157.

Mueller, Dennis C. (1989), Public Choice II (New York: Cambridge University Press).

Mueller, Dennis C. (2001), "On writing a constitution", in Ram Mudambi, Pietro Navarra, and Giuseppe Sobbrio, eds., Rules and Reason: Perspectives on Constitutional Political Economy (Cambridge \& New York: Cambridge University Press), 9-32..

Panagopoulos, Epaminondas P. (1985), Essays on the History and Meaning of Checks and Balances (Lanham: University Press of America).

Rota Graziosi, Grégoire (2001), "Une analyse économique de la sécession", Recherches Economiques de Louvain, Vol. 67, No. 3, 315-350.

Salmon, Pierre (2001a), "Ordinary elections and constitutional arrangements", in Ram Mudambi, Pietro Navarra, and Giuseppe Sobbrio, eds., Rules and Reasons: Perspectives on Constitutional Political Economy (Cambridge \& New York: Cambridge University Press), 165-180.

Salmon, Pierre (2001b), "Constitutional implications of electoral assumptions", Constitutional Political Economy, Vol. 12, no. 4, 333-349.

Tullock, Gordon (1998), On Voting: A Public Choice Approach (Cheltenham, UK: Edward Elgar).

Usher, Dan (1994), "The Significance of the Probabilistic Voting Theorem", Canadian Journal of Economics, Vol. 27, No. 2, May, 433-445.

Vanberg, Viktor J. (1998), "Freiburg School of Law and Economics", in Peter Newman, ed., The New Palgrave Dictionary of Economics and the Law, Volume 2 (London: Macmillan), 172-179.

Voigt, Stefan (1999), Explaining Constitutional Change: A Positive Economics Approach (Cheltenham,UK: Edward Elgar) 
Figure 3.1: Legislator $L_{A}$

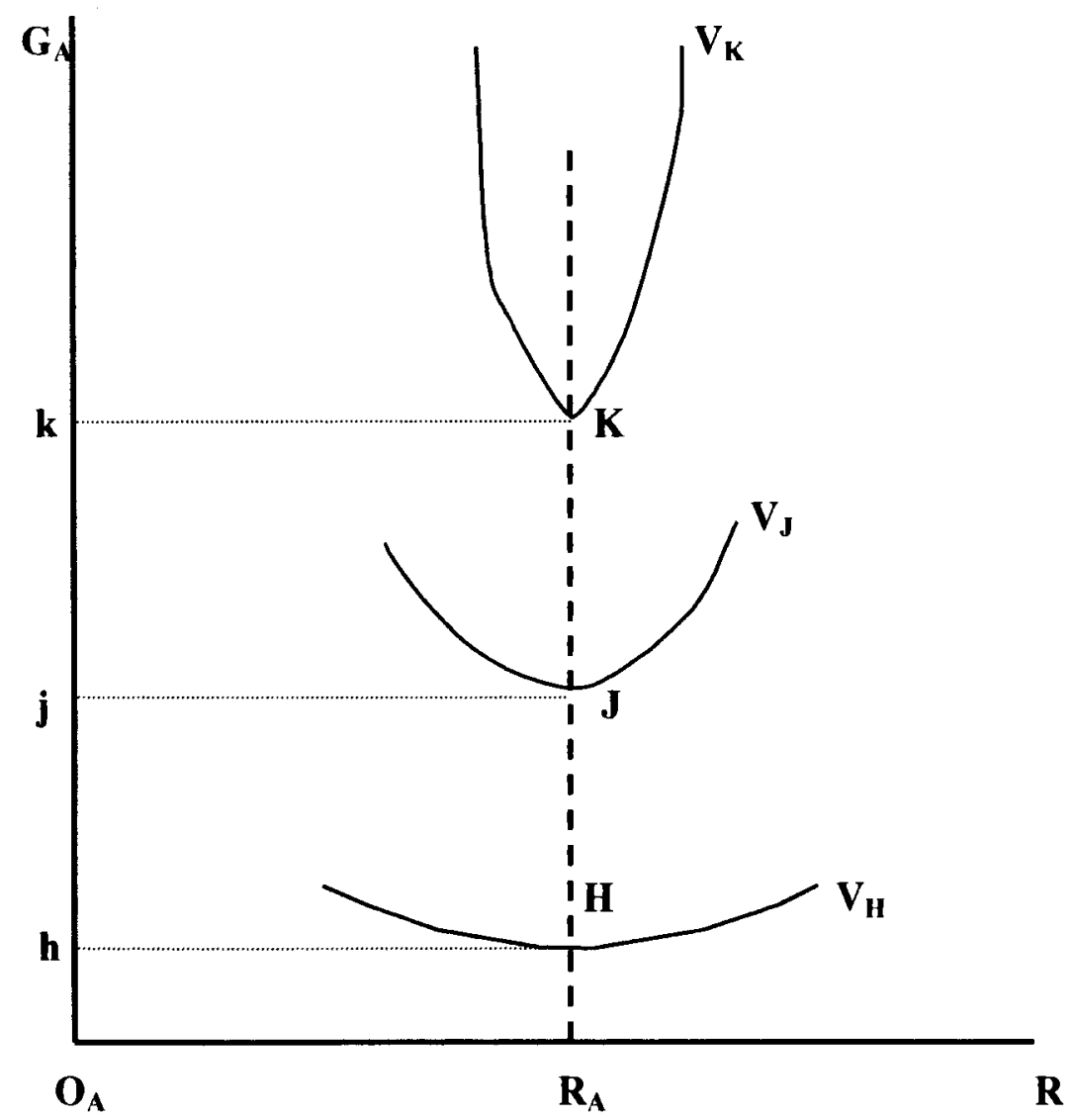


Figure 3.2: The two legislators exchanging goods and services for constitutional characteristics

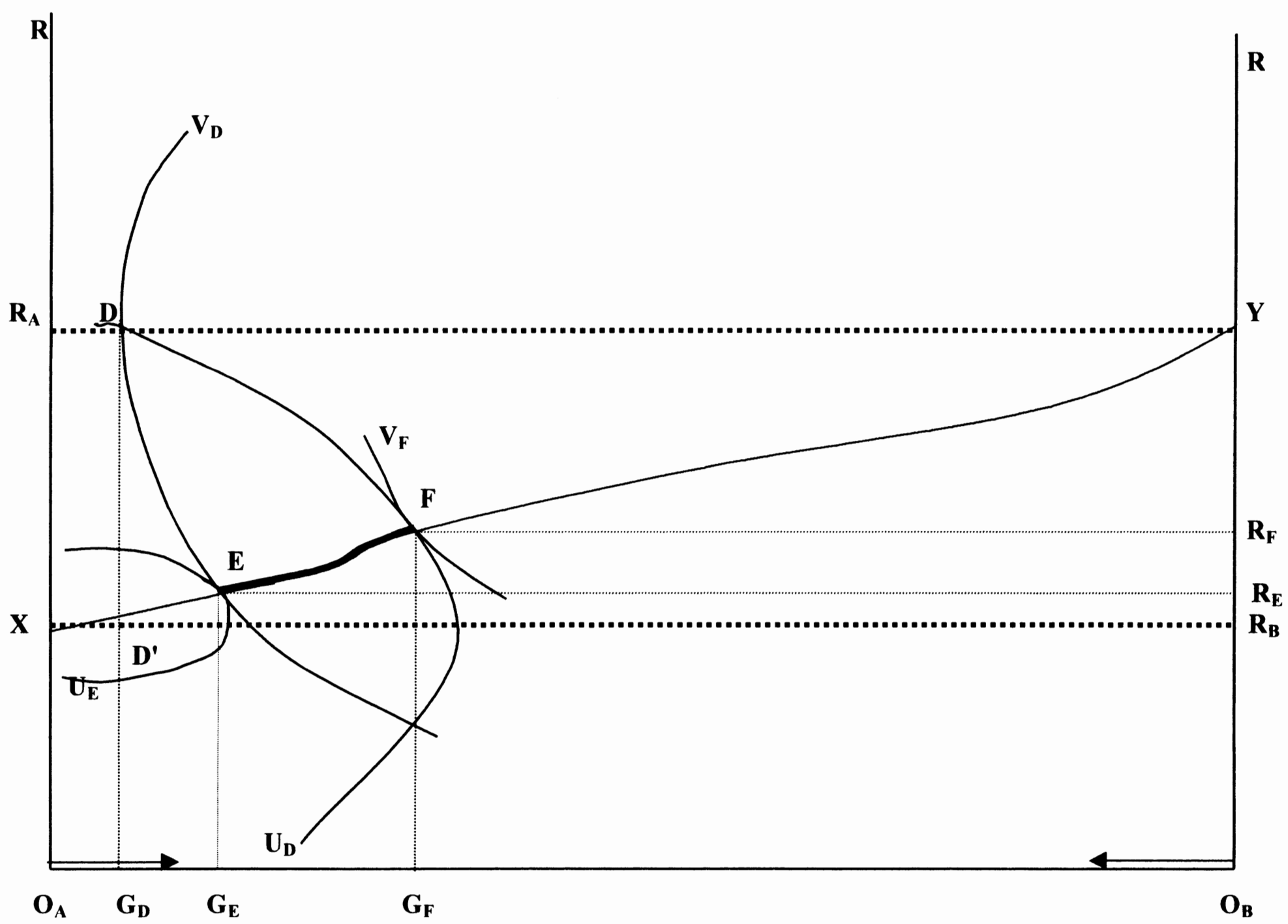




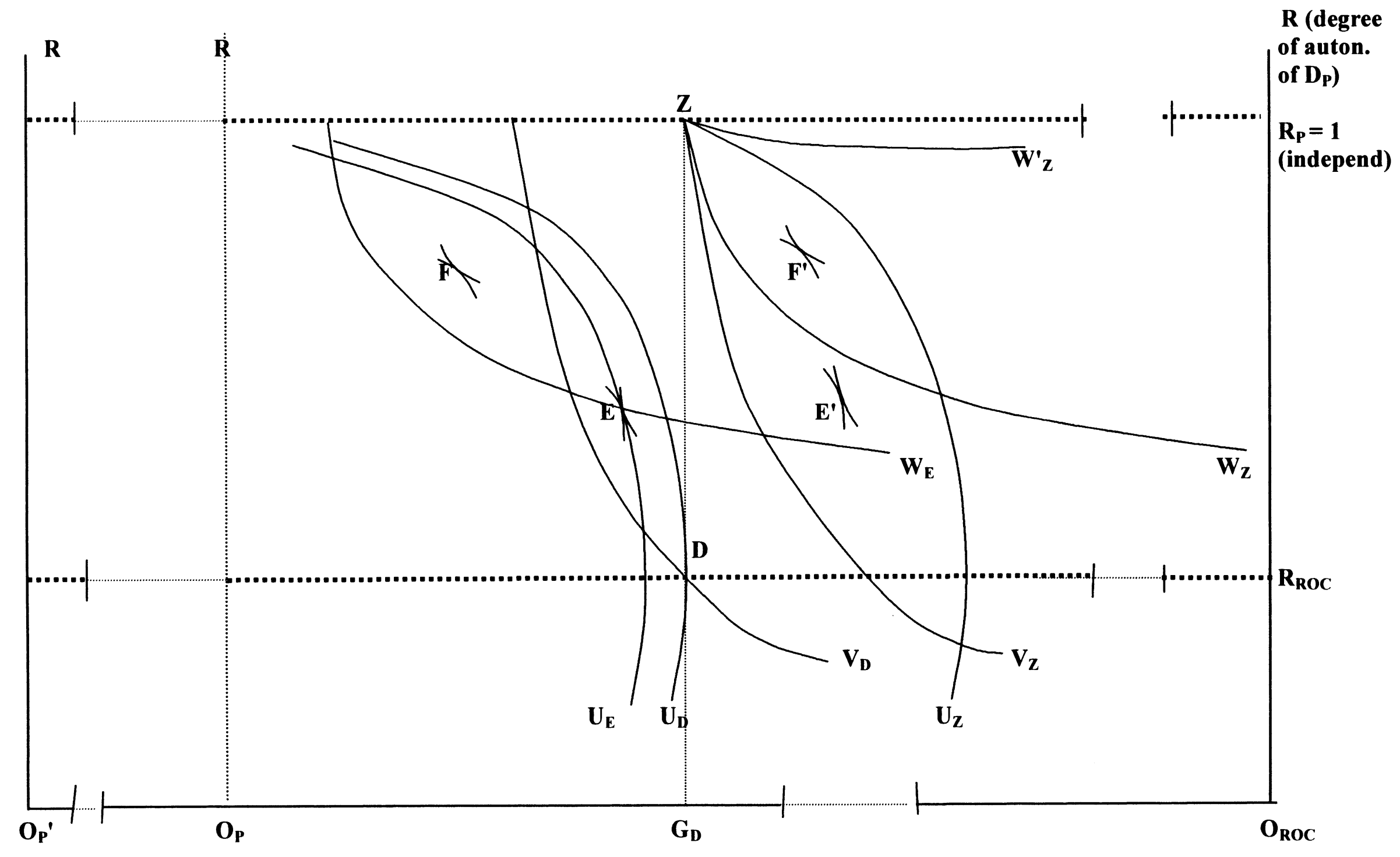

Figure 3.3: Electoral competition and the degree of autonomy of a province 


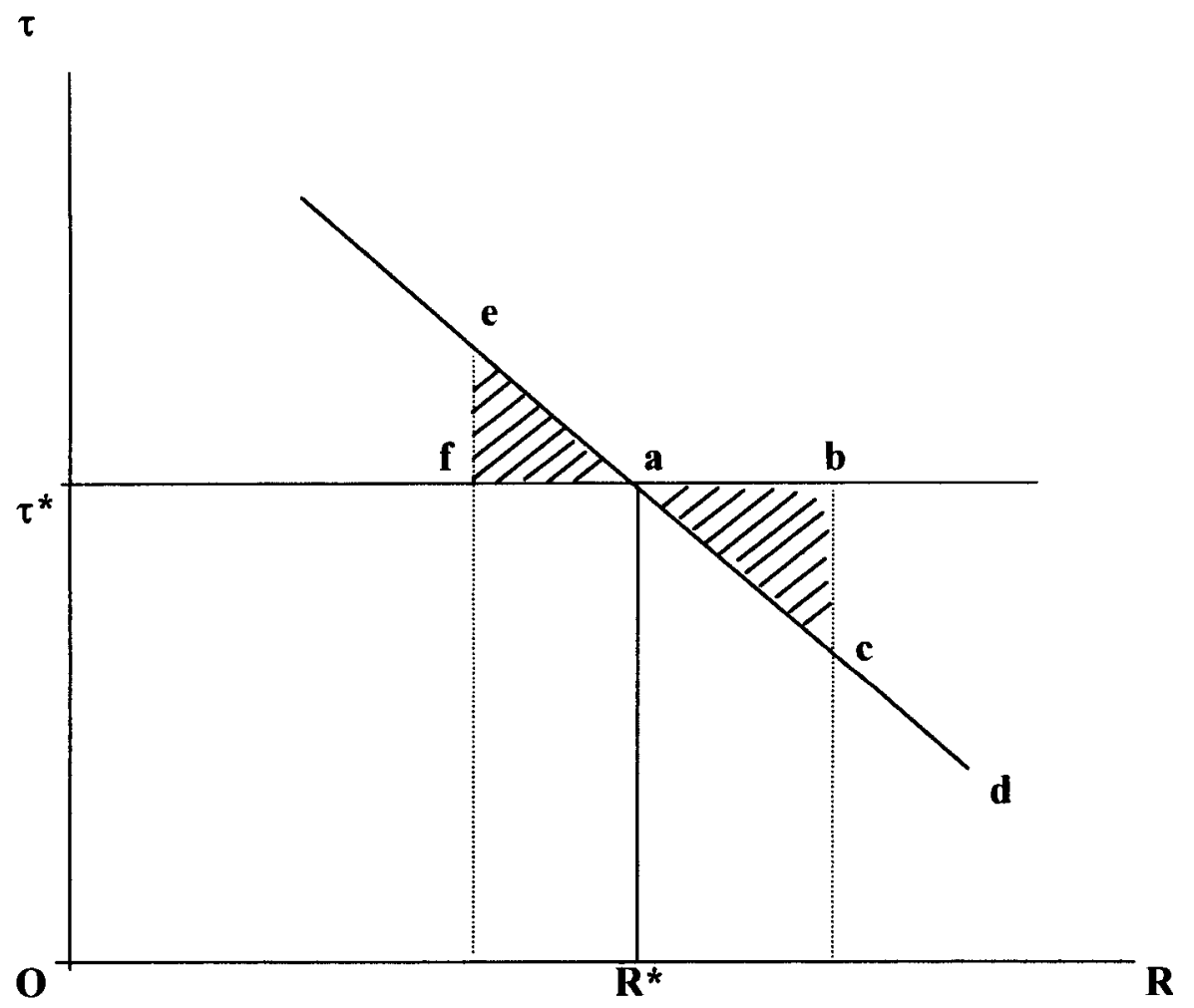

Figure 4.1 


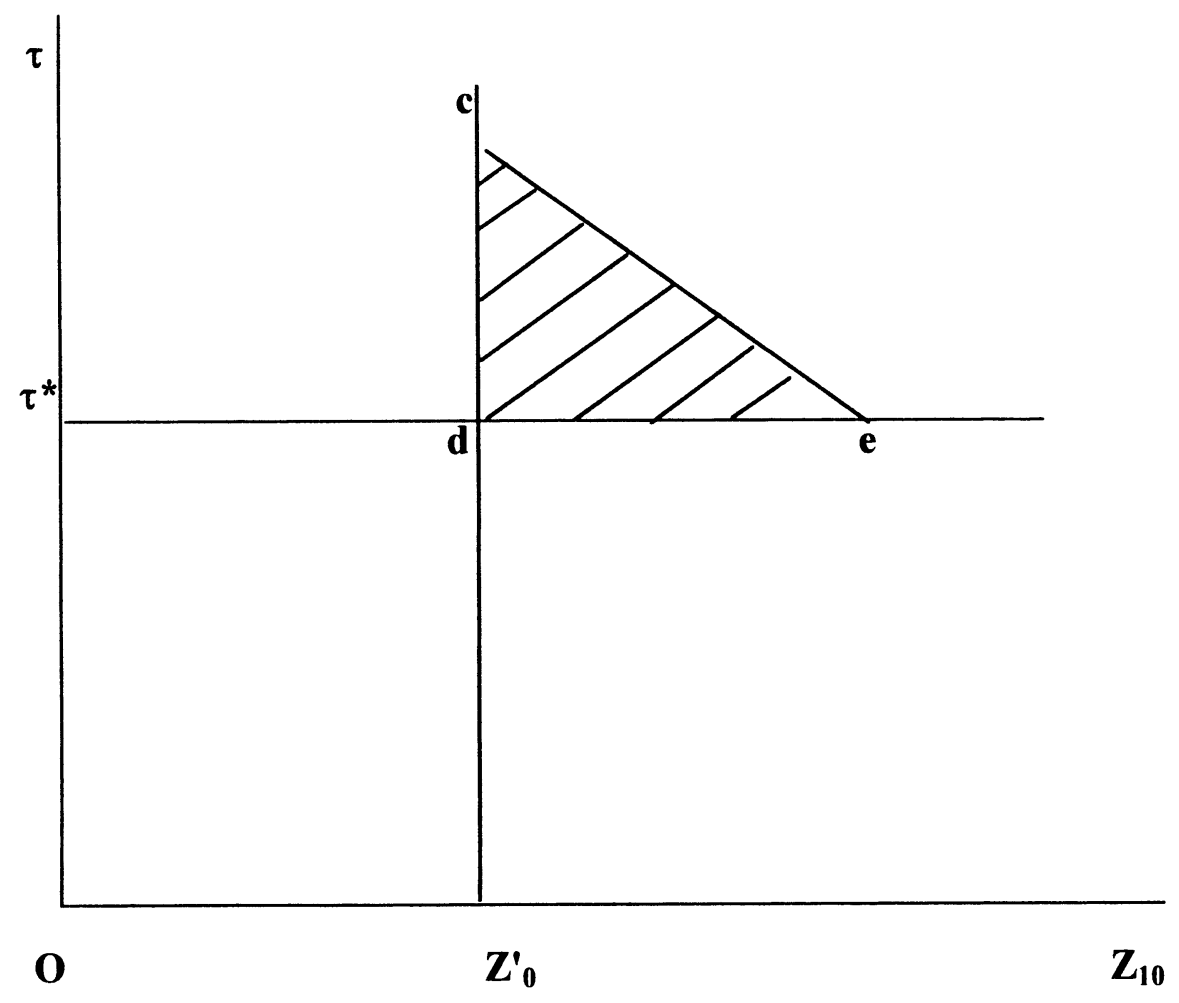

Figure 4. 2 


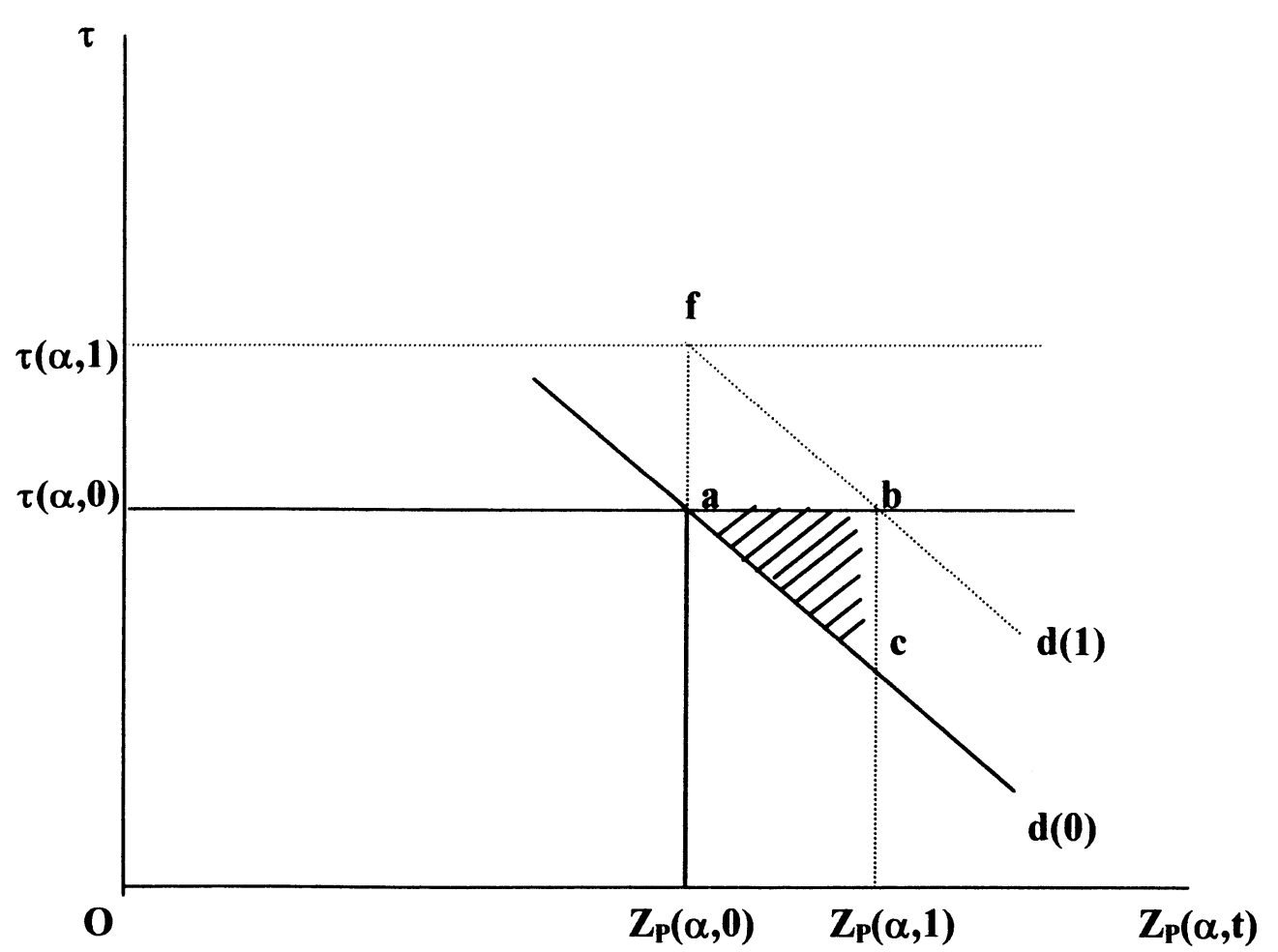

Figure 4. 3 